\title{
Operant response requirements affect touching of visual reinforcement by infants
}

\author{
DIANE C. BAILEY, RICHARD DENI, and AMY FINN-O'CONNOR \\ Rider College, Lawrenceville, New Jersey
}

\begin{abstract}
Studies of instrumental learning in infants have been concerned with negative transfer between noncontingent and contingent learning experiences, sparking debate about the value of responsive environments and calling for measures beyond operant performance to shed light on the underlying perception of contingency. The present studies focused on contingent versus noncontingent stimulation and their effect on attention and consummatory responses as unlearned features of the infant's interaction with stimuli. In each experiment the dependent variable was tactile behavior directed toward pictures, and the independent variable was the type of contingency controlling the pictures. In Experiment 1, 12- to 18- month-old infants were tested in the laboratory using a modified discrete-trial operant procedure in which a touch-sensitive video screen served as both a projection surface and a touch-recording device. Infants touched contingent slides significantly more often than noncontingent slides. Experiment 2 extended this effect to fixedratio 1 (FR-1) versus fixed-ratio 2 (FR-2) schedules of reinforcement. A second group of 12- to 18month-old infants showed a similar pattern; they touched the FR-2 slides significantly more often than the FR-1 slides. These findings indicate that factors other than operant behavior vary as a function of the degree of contingency in an instrumental situation, and hint at possible cognitive processes that compare contingency "rules" governing the responsiveness of a changing environment.
\end{abstract}

A point of concern for researchers studying instrumental learning in infants has been the occurrence of negative transfer between noncontingent and contingent learning experiences. Such negative transfer is similar to "learned helplessness" in laboratory animals and human subjects exposed to noncontingent stimulation prior to the opportunity to learn an operant response. An example of research showing negative transfer is the study by Watson and Ramey (1972), who reported that 2-month-olds, who first viewed noncontingent movements of a mobile, did not acquire an operant response to make the mobile move. Comparable infants, who, during the initial phase, either operated the mobile themselves or simply watched it remain stationary, showed adequate operant learning in the second phase. Similar negative transfer has also been reported following noncontingent exposure to auditory stimuli (DeCasper \& Carstens, 1981).

More recently, research on possible negative transfer effects in infant learning has centered on the issue of the context in which the noncontingent stimulation takes place. Ramey and Finkelstein (1978) showed 3-month-olds noncontingent visual stimuli at home, and then provided the infants an opportunity to exercise operant control over the stimuli in the laboratory by looking at a blank screen to turn on pictures. Contrary to expectation, the infants did learn the operant looking response, and the change in context apparently prevented negative transfer. (Com-

Requests for reprints should be sent to Richard Deni, Study Center for Social and Cognitive Development, Department of Psychology, Rider College, Lawrenceville, NJ 08648-3099. parable procedures with 6- and 9-month-olds done entirely in laboratory-like settings and involving arm and hand operants produced negative transfer [Finkelstein \& Ramey, 1977].) However, Ramey and Finkelstein defended the possibility of negative transfer by raising the issue that performing a spurious "looking" operant was more likely after periods of prolonged looking at stimulating noncontingent pictures. Presumably an exploratory looking behavior triggered operant consequences in the second phase, as a result of the way the procedure was designed, rather than triggering a true perception by infants that they had control over a contingency. Gekoski and Fagen (1984) found another way to prevent negative transfer with 3-month-olds by using different consequences during the noncontingent and contingent phases of the procedure. It appears, then, that the creation or prevention of negative transfer of operant behavior involves a variety of subtle elements beyond the persistence or failure of the operant behavior.

The present studies focused on the role of contingent versus noncontingent stimulation, not from the perspective of possible effects on operant behavior, but from the perspective of changes in attention and consummatory responses. These changes were envisioned as the unlearned features of the infant's interaction with stimuli, whether presented contingently or not. Consummatory behavior toward the consequences of either a contingent or a noncontingent environment can tell researchers a great deal about the underlying processes involved in the operant performance. For example, changes in consummatory behavior may reflect cognitive processes related to how 
difficult the consequence is to activate. One hypothesis we felt would be confirmed in this research was that infants would adjust consummatory behavior according to the degree of effort required to activate consequences (they would "savor" reinforcement that was relatively difficult to produce).

In the present experiments we studied whether motivational changes would be patterned after changes in the degree of contingency in a simple operant task. Visual stimuli were used to keep a degree of comparability with past research. However, looking behavior was not measured. Rather we were concerned with recording attention and consummatory responses involving a different channel, and decided upon tactile behavior directed toward pictures as the dependent variable. The independent variable in both experiments was the type of contingency controlling the presentation of the pictures.

\section{EXPERIMENT 1}

\section{Touching Pictures During Continuous Reinforcement \\ Method}

A group of 13 infants ( 6 boys, 7 girls; $12-18$ months old) was tested in the laboratory in a modified discrete-trial operant procedure. During the procedure each infant sat in the mother's lap facing and well within reach of a small computer screen. When the screen was not illuminated, its surface served as an area on which color slides of the Muppet characters were shown. Each of a large pool of available slides depicted the head and shoulders of a Muppet on a 12-in.-diagonal viewing area. In addition to serving as a projection surface, the screen was touch sensitive and could record the amount of its surface that had been touched. This feature was used to record a "touch score" for tactile behavior directed toward each slide, and to present a lighted operant response "bar" on the screen. Two kinds of slides were available for touching (and viewing). Noncontingent slides simply appeared and stayed on for $10 \mathrm{sec}$. When a contingent slide was scheduled, the operant response bar was drawn first in the amber hue of the touch screen. This bar remained available. When it was touched it disappeared and was followed by immediate slide presentation (also for $10 \mathrm{sec}$ ). Bar touches were reinforced on a continuous or fixed-ratio (FR-1) schedule. The scheduling of noncontingent and contingent trials was counterbalanced, and sufficient trials were scheduled to comprise a maximum session length of $15 \mathrm{~min}$

\section{Results}

The touch data subjected to analysis consisted of the average number of touches on the screen per slide category. A one-factor within-subjects analysis of variance with trials (noncontingent vs. contingent) as the test factor showed that infants touched contingent slides $(M=$ $32.4, S D=16.9)$ significantly more often than noncontingent slides $(M=26.2, S D=11.9)[F(1,12)=5.15$, $p<.05]$.

We believe that touching in this situation was an indicator of interest in, and consumption of, the stimuli. Certainly, the infants were free not to touch the pictures. We also believe the data show that the infants were more vigorous in the consumption of the consequences they produced through operant responding compared with stimulation presented without their intervention.

\section{EXPERIMENT 2}

\section{FR-1 Versus FR-2 Schedules}

\section{Method}

The method described in Experiment 1 was extended to a comparison of two schedules of reinforcement. A second group of 8 infants ( 4 boys, 4 girls; $12-18$ months old) was tested using the same apparatus as in Experiment 1. The only change in the procedure was that all slides were contingent. The operant bar appeared at the onset of each trial. The response requirement for slide presentation was either FR-1 or FR-2 sequenced in a counterbalanced order.

\section{Results}

Although this group of infants touched all slides more vigorously than the group tested in Experiment 1, the FR-2 slides $(M=66.5, S D=33.4)$ were touched significantly more often than the FR-1 slides $(M=59, S D=$ 33.2) $[F(1,7)=6.22, p<.05]$.

\section{DISCUSSION}

These findings indicate that factors other than operant behavior may vary in infants as a function of the degree of contingency in an instrumental performance situation. Our infants did show the expected increase in consummatory behavior with each increase in operant response requirement. These data are provocative because they hint at possible cognitive processes that compare the contingency "rules" governing the responsiveness of a changing environment. Our infants seem to have told us that, as we made pleasurable stimuli progressively harder to obtain, they simply enjoyed each presentation more fully. We do not yet know the role, if any, of consummatory behaviors in the negative transfer effects often seen in infants first given exposure to noncontingent stimulation, but our data may indicate that infants are gathering more information about contingent consequences as they "consume", or attend to them more vigorously.

\section{REFERENCES}

DeCasper, A. J., \& Carstens, A. A. (1981). Contingencies of stimulation: Effects on learning and emotion in neonates. Infant Behavior \& Development, 4, 19-35.

Finkelstein, N. W., \& RAmey, C. T. (1977). Learning to control the environment in infancy. Child Development, 48, 806-819.

Gekoski, M. J., \& FAGEN, J. W. (1984). Noncontingent stimulation, stimulus familiarization, and subsequent learning in young infants. Child Development, 55, 2226-2233.

Ramey, C. T., \& Finkelstein, N. W. (1978). Contingent stimulation and infant competence. Journal of Pediatric Psychology, 3, 98-96.

WATSON, J. S., \& RAMEY, C. T. (1972). Reactions to responsecontingent stimulation in early infancy. Merrill-Palmer Quarterly, 18, 219-227.

(Manuscript received for publication August 12, 1987.) 